\title{
Surface etching of InP(100) by chlorine
}

\author{
Wei-Hsiu Hung ${ }^{\mathrm{a}, *}$, Jyh-Tsung Hsieh ${ }^{\mathrm{b}}$, Huey-Liang Hwang ${ }^{\mathrm{b}}$, Hsin-Yen Hwang ${ }^{\mathrm{c}}$, \\ Che-Chen Chang ${ }^{\mathrm{c}}$ \\ ${ }^{a}$ Synchrotron Radiation Research Center, Science-Based Industrial Park No. 1, R\&D Road VI, Hsin-Chu 30077, Taiwan, ROC \\ ${ }^{\mathrm{b}}$ Department of Electrical Engineering, National Tsing-Hwa University, Hsin-Chu 30077, Taiwan, ROC \\ ' Department of Chemistry, National Taiwan University, Taipei 10764, Taiwan, ROC
}

Received 27 April 1998; accepted for publication 17 August 1998

\begin{abstract}
The cleaning and etching of the $\operatorname{InP}(100)$ surface by chlorine gas is investigated using synchrotron-radiation photoemission spectroscopy. A clean InP surface with a $4 \times 2$ configuration is obtained by ion sputtering or chlorine etching, followed by annealing to $650 \mathrm{~K}$. The clean surface obtained by chlorine etching and annealing is indium-rich with the surface indium atoms showing metallic characterics. The chemisorption of chlorine leads to the formation of various $\operatorname{InCl}_{x}(x=1-3)$ and $\mathrm{PCl}$ species on the InP surface at $110 \mathrm{~K}$ and their corresponding chemical shifts are assigned. The chlorination of the InP surface causes surface band bending by about $0.36 \mathrm{eV}$ at the saturation coverage. Argon-ion sputtering enhances the surface reactivity so that the sputtered surface can be chlorinated to a higher extent than the clean surface. (C) 1998 Elsevier Science B.V. All rights reserved.
\end{abstract}

Keywords: Chlorine; Etching; InP; Synchrotron-radiation photoelectron spectroscopy

\section{Introduction}

InP is an important III-V material in electronics applications because of several advantageous properties. Compared with GaAs, InP has higher peak and saturation electron velocity, higher breakdown voltage, larger intervalley energy gap, smaller ionization coefficient and dielectric constant [1]. When reacted with chlorine, most III-V materials form chlorides on the surface, which are volatile at relatively low temperatures. Therefore, chlorinebased etching is often used in the fabrication of devices based on III-V substrates [2,3]. Whether or not the device has the desired characteristics is

\footnotetext{
* Corresponding author. Fax: + 886-3-5783892; e-mail:whung@alpha1.srrc.gov.tw.
}

determined by the quality of the substrate surface, which influences the nature of the interface in the subsequent fabrication process [4]. Understanding in detail the chemical reaction of the InP surface with chlorine has appreciable technological importance in better handling of this material.

Among the different crystal faces, the $\operatorname{InP}(100)$ surface is the most important face with respect to its application in optoelectronic devices. However, similar to the GaAs(100) surface, the $\operatorname{InP}(100)$ surface can be reconstructed into several configurations in a complex way $[5,6]$. It is now well known that ion bombardment and heating result in an indium-rich surface $[1,7,8]$. Depending on the annealing temperature, there are two surface reconstructions that can be observed for the indium-rich surface $[9,10]$. The $\operatorname{InP}(100)$ surface 
is sufficiently ordered to exhibit a $(4 \times 2)$ lowenergy electron diffraction (LEED) pattern after argon-ion bombardment and gentle annealing. In spite of various structures proposed in previous studies, the detailed structure of the $\operatorname{InP}(100)-4 \times 2$ surface is still unclear [6]. Based on the model proposed for the surface structure of $\operatorname{GaAs}(100)$, a qualitative missing-row-dimer (MRD) structure has been discussed for the $\operatorname{InP}(100)-4 \times 2$ surface [11-13]. It has been suggested that the surface is covered by some metallic indium atoms $[1,14]$. The presence of metallic indium atoms on the InP surface may be crucial for obtaining the desired quality of interface for further fabrication [15]. In this study, X-ray photoelectron spectroscopy (XPS) is used to elucidate the nature of the $\operatorname{InP}(100)-4 \times 2$ surface and its reaction with $\mathrm{Cl}_{2}$.

Furthermore, in contrast to GaAs, a remote chlorine plasma does not etch InP efficiently at temperatures below $125^{\circ} \mathrm{C}$ [16,17]. It is concluded that the difference in volatility of the etch products gives rise to the differences in both the etching threshold temperature and the temperature dependence of the etching rate for GaAs and InP. A previous temperature-programmed desorption (TPD) study of the chlorinated InP surface showed that the two desorption peaks ( $\alpha$ and $\beta$ states) of $\mathrm{InCl}$ and $\mathrm{P}_{4}$ are observed at 410 and $570 \mathrm{~K}$ during thermal desorption [18]. The populations of $\alpha$ and $\beta$ states are very sensitive to the structure and stoichiometry of the surface. This investigation of the reaction of the InP surface with $\mathrm{Cl}_{2}$ may provide a better understanding of the difference in etching rates of chlorine between the GaAs and InP surfaces.

Energetic ions have been used to enhance the etching rate of various material surfaces [19]. Argon-ion beams are extensively used for ionassisted dry etching of semiconductors because of their chemical inertness and high sputtering yield [20]. On the other hand, the chemical and physical damage on the surface after reactive-ion etching (RIE) may cause undesirable surface properties. The damage can be reduced by a post-RIE process or removed through a thermal reaction with chlorine, which generates volatile chlorides [21]. Thus it is of considerable importance to study in detail the effect of ion bombardment on the interaction of the InP surface with chlorine gas.

Chlorine is also used in the low-temperature RIE process to obtain a less-damaged etched InP surface with good anisotropy and smooth stoichiometry [22]. Since Group III and V chlorides are volatile, they may desorb from the surface after being formed during $\mathrm{Cl}_{2}$ exposure, without resorting to a vigorous thermal treatment. Therefore, when the InP is etched, the substrate temperature can be kept low so that the chlorides formed on the surface of the side wall can remain intact for better anisotropic etching profile [23]. The advantage of etching at low temperatures also includes the fact that the sticking coefficient of $\mathrm{Cl}_{2}$ on the InP surface is increased at low temperature. All the experiments in this study were thus performed by cooling the InP sample with liquid nitrogen to $110 \mathrm{~K}$. Results obtained from the low-temperature study may provide clues to the fundamental surface chemistry of chlorine etching, which may eventually help in process design.

\section{Experimental}

Experiments were performed in an ultrahigh vacuum (UHV) chamber equipped with a quadrupole mass spectrometer, a low-energy electron diffractometer and a VG CLAM II electron-energy analyzer. The XPS measurements were carried out at the $6 \mathrm{~m}$ LSGM beamline of SRRC (Synchrotron Radiation Research Center, Taiwan). The incident angle of photons was $55^{\circ}$ from the surface normal. The emitted photoelectrons were collected with the electron analyzer normal to the sample surface. The InP sample was mounted on the tantalum plate by indium bonding, to achieve good contact. The sample can be cooled to $110 \mathrm{~K}$ with liquid nitrogen and heated by electron beam bombardment from the back of the tantalum plate. The surface temperature was measured by using a K-type thermocouple spot-welded close to the sample. The $\operatorname{InP}(100)$ sample (S-doped n-type, $\sim 3 \times 10^{18} \mathrm{~cm}^{-3}$ ) was cleaned by chemical etching using sulfuric acid and hydrogen peroxide solution. The etched InP sample was rinsed in deionized water and was cleaned by argon-ion bombardment 
$(500 \mathrm{eV})$ with the ion beam at a $45^{\circ}$ incident angle in UHV. Following $\mathrm{Ar}^{+}$-ion bombardment, the sample was annealed to $\sim 650 \mathrm{~K}$ for $2 \mathrm{~min}$. A $4 \times 2$ LEED pattern was observed, which is characteristic of an indium-rich InP(100) surface. For exposure of the sample to $\mathrm{Cl}_{2}$, the chlorine gas was introduced to the $\operatorname{InP}(100)$ surface by background dosing through a leak valve.

All XPS spectra were taken at a sample temperature of $110 \mathrm{~K}$. The spectra collected were fitted numerically with Gaussian-broadened Lorentzian spin-orbit doublets after Shirley background subtraction with a third-order polynomial to each side of the peak in all fits [24]. The Lorentzian full-width at half-maximum (FWHM) was fixed at $0.15 \mathrm{eV}$ for In $4 d$ and $0.10 \mathrm{eV}$ for $\mathrm{P} 2 p$. The peak width of each core-level component is mainly determined by the Gaussian FWHM. The spinorbit splitting values are $0.85 \mathrm{eV}$ for In $4 d$ and $0.86 \mathrm{eV}$ for $\mathrm{P} 2 p$.

\section{Results and discussion}

Fig. 1 shows the core-level spectra of In $4 d$ and $\mathrm{P} 2 p$ for the $\operatorname{InP}(100)$ surface sputtered by $500 \mathrm{eV}$ $\mathrm{Ar}^{+}$ions for $30 \mathrm{~min}$ and then annealed to $650 \mathrm{~K}$. The photon energy used to collect these spectra is $50 \mathrm{eV}$ for $\mathrm{In} 4 d$ and $160 \mathrm{eV}$ for $\mathrm{P} 2 p$. Photoelectrons from In $4 d$ and $\mathrm{P} 2 p$ are all measured at about $30 \mathrm{eV}$. Thus, the analyzing depth of the InP substrate for both the In $4 d$ and P $2 p$ spectra is about the same.

The assignments of the XPS spectra for the clean $\operatorname{InP}(100)-4 \times 2$ surface are necessary for the interpretation of the chemical species formed on the InP surface upon the adsorption of chlorine. The indium spectra are best fitted with the branching ratio of $0.68 \pm 0.02$. From our curve fitting, the XPS spectrum of a clean $\operatorname{InP}(100)-4 \times 2$ surface shows several indium chemical components with the $4 d_{5 / 2}$ binding energies at 16.92, 17.27, 17.67 and $17.86 \mathrm{eV}$, as shown in Fig. 1. The peak with a binding energy at $17.67 \mathrm{eV}$ is obtained due to the contribution from the bulk InP. The peaks with binding energies at $16.92,17.27$ and $17.86 \mathrm{eV}$ are attributed to metallic indium atoms and indium adatoms with dangling bonds ( $\mathrm{S} 1$ and $\mathrm{S} 2$ ) on the
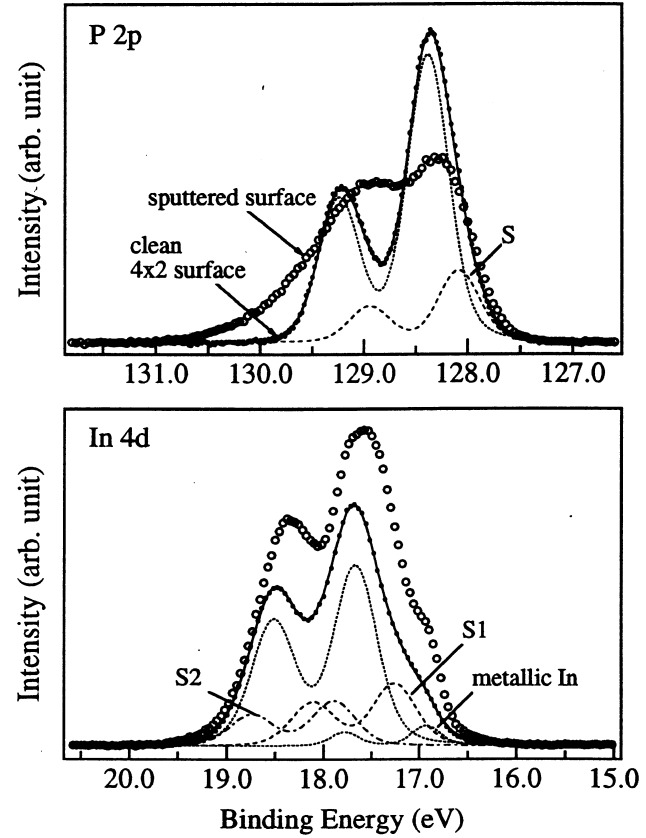

Fig. 1. Soft X-ray photoelectron spectra of In $4 d$ and P $2 p$, collected from an InP(100) surface after the sample had been either bombarded by $500 \mathrm{eV} \mathrm{Ar}^{+}$ions for $30 \mathrm{~min}$ or sputtered and annealed to $650 \mathrm{~K}$. The photon energy used to collect these spectra is $50 \mathrm{eV}$ for the In $4 d$ level and $160 \mathrm{eV}$ for the $\mathrm{P} 2 p$ level. The dots represent the data collected after background subtraction, the solid line is the curve fit to the data, and the various components are shown by dashed lines. The surface-shifted core-level components of indium and phosphorus are labeled $\mathrm{S} 1, \mathrm{~S} 2$ and S, respectively.

surface, respectively. A Gaussian FWHM of $0.27 \pm 0.02 \mathrm{eV}$ is used for the metallic indium atoms in all In $4 d$ spectra. This width is significantly smaller than that obtained for bulk and surface indium $(0.45 \pm 0.02 \mathrm{eV})$. The value of the Gaussian FWHM for the metallic indium component is obtained from a well-resolved spectrum of the chlorinated InP surface which is to be discussed later. The P $2 p$ spectrum can be fitted well with a branching ratio of $0.50 \pm 0.01$ for $p_{1 / 2}$ and $p_{3 / 2}$, and the binding energy of the surface core-level component is shifted from that of the bulk by $-0.31 \mathrm{eV}$.

The intensities of In $4 d$ and P $2 p$ for the clean and sputtered surfaces, shown in Fig. 1, are normalized to the photon flux. For the sputtered surface, there is an increase in the intensity at the low-binding-energy side of the In $4 d$ spectrum, 
whereas a broad tail appears at high binding energy in the $\mathrm{P} 2 p$ spectrum. There has been some dispute over the composition of a sputtered InP surface $[1,10,25-29]$. We make no attempt to deconvolute the spectra of a sputtered InP surface because of the complication of the surface composition (stoichiometry of indium and phosphorus) and roughness due to the energetic-ion bombardment. The long tail of $\mathrm{P} 2 p$ at the high-bindingenergy side may suggest the presence of $\operatorname{InP}_{x}$ with a phosphorus-rich stoichiometry or phosphorus adatoms on the sputtered and roughened surface, which has higher binding energy than the bulk phosphorus atoms.

In this study, a $4 \times 2$ LEED pattern with large, weak half-order spots is obtained on the clean $\mathrm{InP}(100)$ sample after argon-ion sputtering and annealing to $650 \mathrm{~K}$. This suggests that the clean InP surface obtained in this study is not perfectly ordered. Its surface geometry may be considered as a $4 \times 2$ structure, on which the $c(8 \times 2)$ structure is present $[11,30,31]$. The metallic indium clusters may be present on the surface and thus hinder the complete reconstruction of the $c(8 \times 2)$ structure [32]. This surface structure is expected to be the most stable structure on the (100) III-V semiconductor surface at high temperatures, and has been observed on the GaAs(100) surface before [33,34]. In addition, the LEED pattern obtained reveals that the area of the ordered surface domains may be close to or less than the coherence width ( $\sim 100 \AA$ ) of the electron beam source used in the LEED experiment [35]. Metallic indium clusters may thus be somewhat randomly distributed on the surface at a distance which, on average, is less than the coherence width.

Figs. 2 and 3 show the XPS spectra for In $4 d_{5 / 2}$ and $\mathrm{P} 2 p$ of an $\operatorname{InP}(100)-4 \times 2$ surface exposed to various amounts of chlorine at $110 \mathrm{~K}$. For simplicity and clarity, only the $4 d_{5 / 2}$ component obtained from deconvolution of the experimental data is presented in Fig. 2 for the In $4 d$ spectra [36]. As evident from the significant changes in both the In $4 d$ and $\mathrm{P} 2 p$ spectra with chlorine exposure, chlorination occurs on both the indium and phosphorus atoms upon the adsorption of chlorine. The chlorine-induced components appear at high binding energy, which is indicative of the forma-

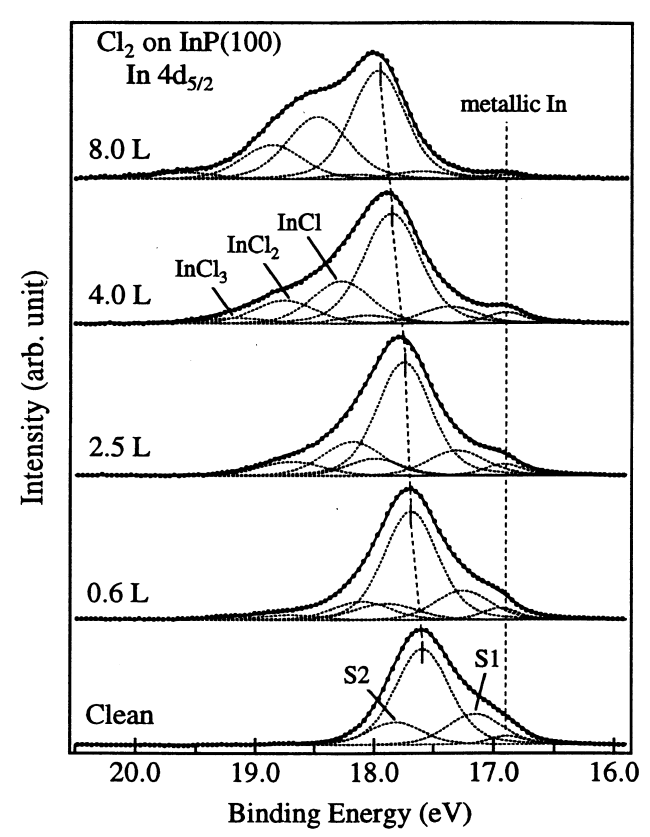

Fig. 2. Soft X-ray photoelectron spectra of In $4 d_{5 / 2}$ from the $\operatorname{InP}(100)-4 \times 2$ surface with various exposures to $\mathrm{Cl}_{2}$ at $110 \mathrm{~K}$.

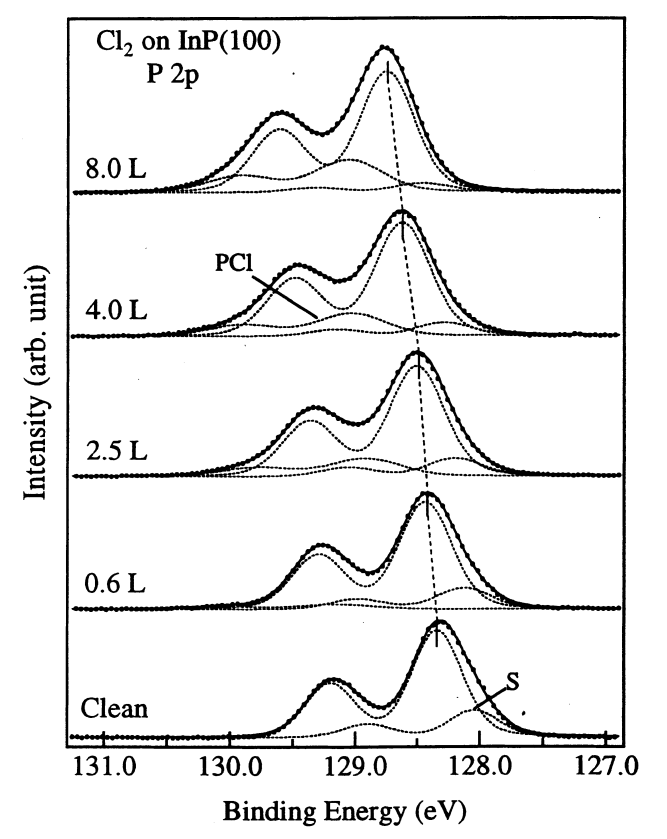

Fig. 3. Soft X-ray photoelectron spectra of $\mathrm{P} 2 p$ from the $\operatorname{InP}(100)-4 \times 2$ surface with various exposures to $\mathrm{Cl}_{2}$ at $110 \mathrm{~K}$. 
tion of indium and phosphorus chlorides. From our data fitting, the chemical shifts of indium chlorides with respect to that of the bulk InP are $0.44,0.86$ and $1.36 \mathrm{eV}$. These shifts are attributed to the formation of $\mathrm{InCl}, \mathrm{InCl}_{2}$ and $\mathrm{InCl}_{3}$ on the surface. For the phosphorus components, as shown in Fig. 3, only a $\mathrm{PCl}$ species is formed on the surface upon chlorine adsorption. This species has a chemical shift of $0.34 \mathrm{eV}$ from the bulk InP. The intensities of the peaks due to the clean surface indium and phosphorus atoms decrease with increasing $\mathrm{Cl}_{2}$ exposure. The chlorination of $\operatorname{InP}(100)$ is saturated when the surface is exposed to chlorine of more than $10 \mathrm{~L}$ at $110 \mathrm{~K}$. At higher exposures, a passivation layer of indium and phosphorus chlorides is formed, and molecular chlorine physisorbs and accumulates on the surface.

With the increase of $\mathrm{Cl}_{2}$ exposure, the peaks assigned to bulk In $4 d$ and $\mathrm{P} 2 p$ shift to higher binding energies than that of the clean surface. The shift of the bulk indium and phosphorus components relative to the spectra of the clean surface is due to the occurrence of the surface band bending, which induces a change in the binding energy of the core level relative to the Fermi level [36]. The chemisorption of chlorine with strong electronegativity may cause a change in the electrostatic potential and result in a shift of the core level of the bulk InP to higher binding energy. The surface band bending increases with the extent of chlorination, i.e., the exposure to chlorine. On the chlorine-saturated InP surface, the binding energies of the bulk In $4 d$ and $\mathrm{P} 2 p$ are lifted by about $0.36 \mathrm{eV}$ from the clean $\operatorname{InP}(100)-4 \times 2$ surface. It was reported that the adsorption of $\mathrm{Cl}_{2}$ on a cleaved $\operatorname{InP}(110)$ surface caused a downshift of the Fermi level by $0.2-0.3 \mathrm{eV}$ from the conduction band [15]. The binding energy of the component assigned to metallic indium remains essentially unchanged on the chlorinated surface. This suggests that the metallic indium atoms, however, remain as clusters on the InP surface and act as individual systems. These clusters are not affected by the average electrical field felt by the indium and phosphorus atoms in the bulk and surface InP.

To achieve a good fitting of the collected In $4 d$ and $\mathrm{P} 2 p$ spectra from the chlorinated InP surface, it is necessary to include the components with shifts in binding energies from the substrate peak of -0.4 and $0.2 \mathrm{eV}$ for the indium atom and $-0.32 \mathrm{eV}$ for the phosphorus atom. These shifts in binding energy are due to the presence of adatoms with dangling bonds on the clean surface, which persist on the surface with saturated chlorination. Similar persistence of these components was also observed for the GaAs surfaces exposed to $\mathrm{XeF}_{2}$ and to $\mathrm{Cl}_{2}$ [37,38]. They were attributed to the gallium and arsenic atoms generated on the substrate with a tri-coordinated configuration as a result of the bond breaking during halogenation, which have similar binding energy shifts as the surface-induced chemical shifts. During chlorination, the bond breaking of In-P occurs at the interface between the bulk and the chloride layer. Consequently, the tri-coordinated atoms are created and the chloride layer grows. At a $\mathrm{Cl}_{2}$ exposure of more than $10 \mathrm{~L}$, the thick indium and phosphorus chloride layer may become passivated, and chlorine cannot react further with bulk InP and tri-coordinated atoms.

The intensities of surface components decrease with increasing chlorine exposures. At initial chlorination, the intensity of the surface indium adatoms (S1 and S2) in In $4 d$ spectra decreases more drastically than that of the metallic indium atoms. During this time, most of the adsorbed chlorine reacts with the surface indium adatoms to form indium chlorides. This is consistent with the argument that the metallic indium atoms concentrate in droplets, rather than in a continuous film, and cover a small fraction of the surface area. Since some metallic indium atoms can persist even at the saturation coverage, the indium atoms inside the droplet may be relatively inert to further chlorination after a chlorinated passivation layer on the outside is formed at a temperature as low as $110 \mathrm{~K}$.

Indium and phosphorus chlorides are observed on the InP surface at low exposures of chlorine, and there is no obvious preference of the chlorination with either surface indium or phosphorus atoms. Among the indium chlorides, $\mathrm{InCl}$ and $\mathrm{InCl}_{2}$ are the main products and only a small amount of $\mathrm{InCl}_{3}$ is formed. $\mathrm{PCl}$ is the only product of the phosphorus chlorides. However, by compar- 
ing the chloride intensity to the bulk intensity, it is found that the chlorinated InP surface is mainly composed of indium chlorides. The preferential formation of indium chlorides upon chlorine adsorption may result from the domination of the indium atoms on the clean InP surface. This suggests that the clean InP surface is mainly covered by the indium atoms, as described above.

Figs. 4 and 5 show the XPS spectra of In $4 d_{5 / 2}$ and $\mathrm{P} 2 p$ for an $\operatorname{InP}(100)-4 \times 2$ surface exposed to $8 \mathrm{~L} \mathrm{Cl}_{2}$ at $110 \mathrm{~K}$, followed by warming up to the indicated temperatures. When the substrate is heated up to $250 \mathrm{~K}$, the intensity of the metallic indium atoms at $16.92 \mathrm{eV}$ is diminished while the intensity of indium chlorides increased. This suggests that the metallic indium clusters can be decomposed by further reacting with the physisorbed chlorine to form more indium chlorides upon thermal annealing. When the surface is heated up to $400 \mathrm{~K}, \mathrm{InCl}_{3}$ is completely depleted and a small amount of $\mathrm{InCl}$ and $\mathrm{InCl}_{2}$ desorbs from the surface. A well-resolved peak at $16.9 \mathrm{eV}$

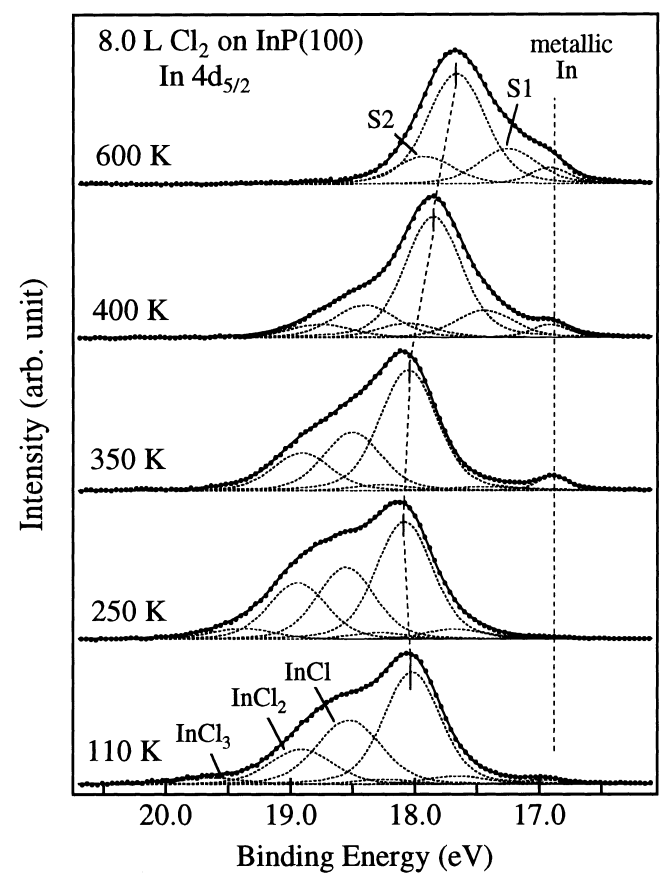

Fig. 4. Soft X-ray photoelectron spectra of In $4 d_{5 / 2}$ from the $\operatorname{InP}(100)$ surface exposed to $8 \mathrm{~L} \mathrm{Cl}_{2}$ at $110 \mathrm{~K}$, followed by annealing the substrate to $250 \mathrm{~K}, 350 \mathrm{~K}$ or $400 \mathrm{~K}$.

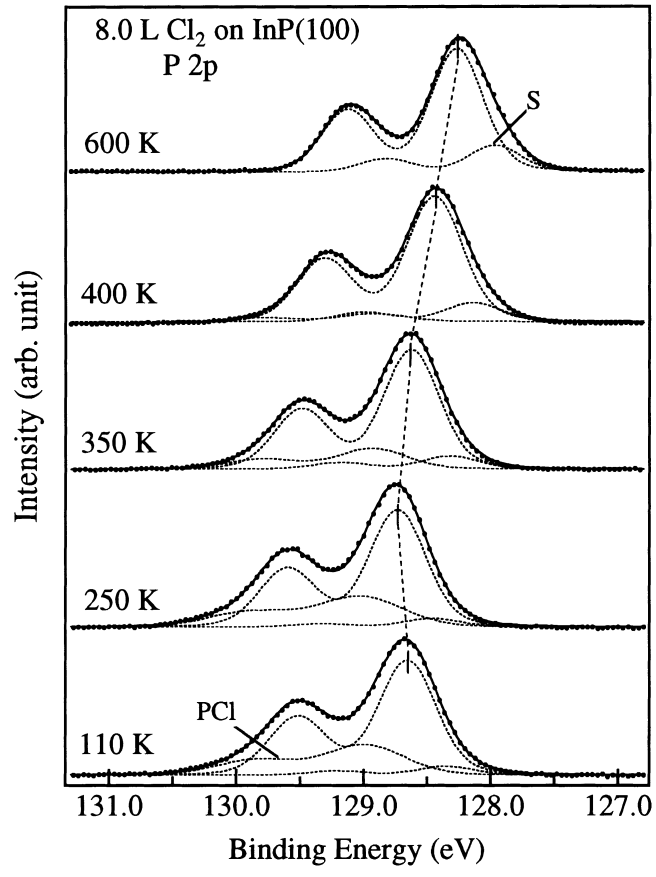

Fig. 5. Soft X-ray photoelectron spectra of $\mathrm{P} 2 p$ from the $\operatorname{InP}(100)$ surface exposed to $8 \mathrm{~L} \mathrm{Cl}_{2}$ at $110 \mathrm{~K}$, followed by annealing the substrate to $250 \mathrm{~K}, 350 \mathrm{~K}$ or $400 \mathrm{~K}$.

is observed at $350 \mathrm{~K}$ with a Gaussian FWHM of $0.27 \mathrm{eV}$, which is smaller than that of bulk InP. It has been also observed that large metallic indium droplets exist on the heavily hydrogenated InP surface [14,39-41]. The FWHM of the metallic In $4 d$ peak is smaller than in bulk InP due to the difference of their bonding character. Fig. 4 thus indicates that the metallic indium droplets reappear on the surface during the desorption of indium chlorides. The FWHM of the peak at $16.9 \mathrm{eV}$ is used in the curve fitting of the metallic indium component in all In $4 d$ spectra.

When the surface is annealed to $600 \mathrm{~K}$, all indium and phosphorus chlorides desorb from the surface and a blurred $\operatorname{InP}(100)-4 \times 2$ surface is recovered, like that obtained by ion bombardment and annealing. The surface band bending is reduced when the sample is heated to desorb surface chlorides. The regeneration of the clean surface is thus accomplished by thermal desorption of surface indium and phosphorus chlorides. The results indicate that, when the substrate is annealed 
above $600 \mathrm{~K}$, the indium-rich surface covered with metallic indium atoms is the favorable configuration thermodynamically.

The XPS spectra shown in Figs. 4 and 5 suggest that the desorption of surface chlorides from the chlorinated InP surface occurs over a very wide temperature range. It may consist of more than one desorption stage. In a previous TPD study, it was found that the desorption was a two-stage process including $\alpha$ and $\beta$ states [20]. The desorption of the $\alpha$ state started at $\sim 350 \mathrm{~K}$ and the $\beta$ state desorbed at $\sim 500 \mathrm{~K}$. Two phases of chlorides may thus be present on the surface. The $\alpha$ state was attributed to the chemisorbed adlayer and the $\beta$ state the bulk corrosion phase. It also showed that the population of these two states is strongly dependent on the preparation of the InP surface. Bombardment of the InP surface with $\mathrm{Ar}^{+}$ions resulted in an increase of the $\alpha$ state. This study shows that, since the bombardment induces the formation of metallic indium as described above, the $\alpha$ state may be attributed to the indium chlorides formed due to the reaction of metallic indium with chlorine. The $\beta$ state may be attributed to a mixed phase of indium and phosphorus chlorides, which is formed from the reaction of both the surface and the bulk InP with chlorine. This assignment is in contrast to the previous one [20]. Since the clean surface, which is an indium-rich surface containing indium droplets, can be obtained after annealing the chlorinated surface to $600 \mathrm{~K}$, desorption of surface phosphorus atoms must have occurred during the thermal annealing after chlorides desorb. In fact, it was found that $\mathrm{P}_{4}$, instead of $\mathrm{PCl}$, was the desorption product of phosphorous species in the thermal desorption, and its desorption temperature was marginally higher than that of indium chlorides [20]. This implies that, during the thermal annealing, the chlorine atoms in $\mathrm{PCl}$ are transferred to the indium atoms nearby to form gaseous indium chlorides. The phosphorus atoms left on the surface thus desorb to restore a surface stoichiometry of indium enrichment, which is thermodynamically stable. The desorption of indium chlorides, rather than phosphorus chloride, may be due to the stronger bonding energy of $\mathrm{In}-\mathrm{Cl}\left(E_{\mathrm{dis}}=4.5 \mathrm{eV}\right)$ than that of $\mathrm{P}-\mathrm{Cl}$ $\left(E_{\mathrm{dis}}=3.0 \mathrm{eV}\right)[42]$.

Figs. 6 and 7 show In $4 d$ and P $2 p$ spectra taken

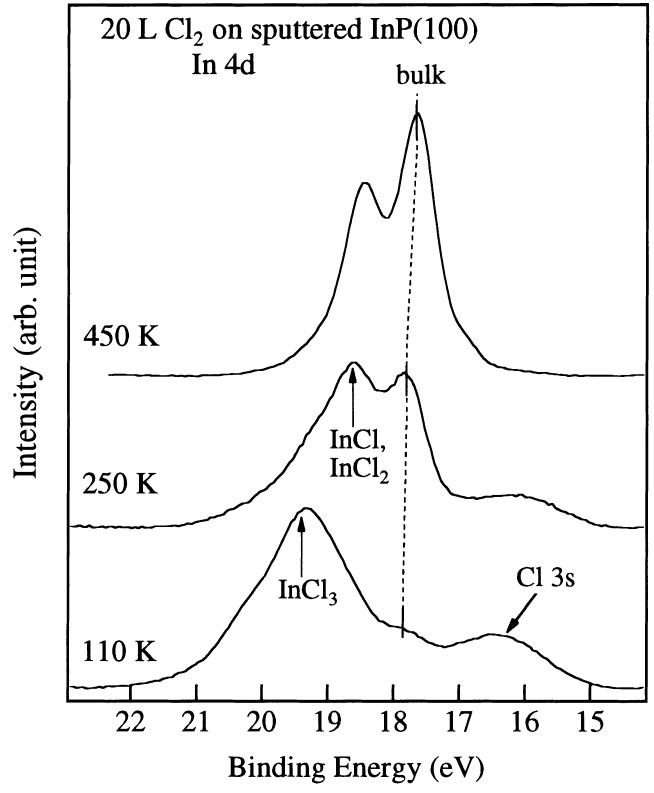

Fig. 6. Soft X-ray photoelectron spectra of In $4 d_{5 / 2}$ from the sputtered $\operatorname{InP}(100)$ surface exposed to $20 \mathrm{~L} \mathrm{Cl}_{2}$ at $110 \mathrm{~K}$, followed by annealing the substrate to $250 \mathrm{~K}$ or $450 \mathrm{~K}$.

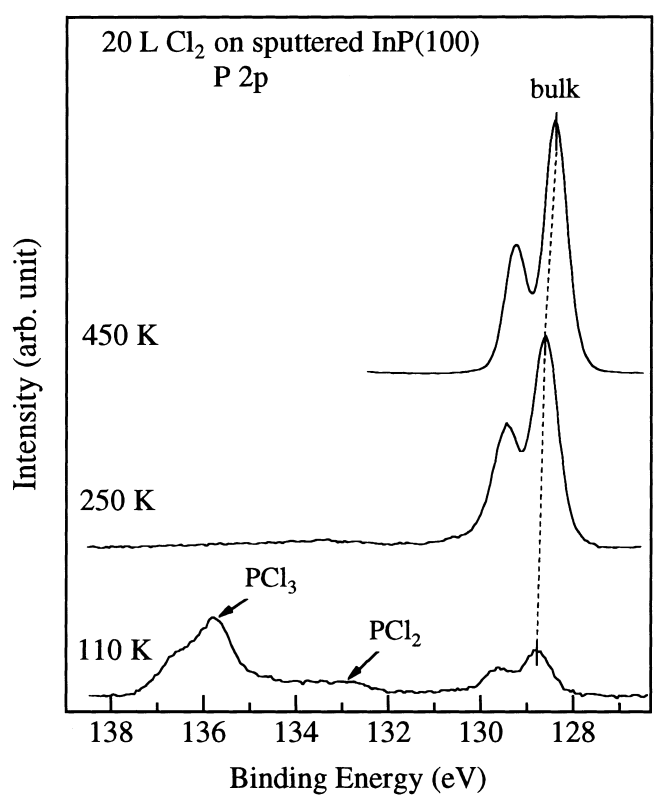

Fig. 7. Soft X-ray photoelectron spectra of $\mathrm{P} 2 p$ from the sputtered $\operatorname{InP}(100)$ surface exposed to $20 \mathrm{~L} \mathrm{Cl}_{2}$ at $110 \mathrm{~K}$, followed by annealing the substrate to $250 \mathrm{~K}$ or $450 \mathrm{~K}$. 
from a bombarded InP surface which was exposed to $20 \mathrm{~L} \mathrm{Cl}_{2}$ at $110 \mathrm{~K}$, followed by being annealed to $250 \mathrm{~K}$ or $450 \mathrm{~K}$. Upon the adsorption of chlorine on the bombarded surface, the intensities of bulk indium and phosphorus are attenuated by the thick indium and phosphorus chloride layer. Fig. 6 shows that a large amount of $\mathrm{InCl}_{3}$ is formed on the bombarded surface. This is in contrast to that observed from the sputtered and annealed surface on which $\mathrm{InCl}_{2}$ and $\mathrm{InCl}$ dominate after chlorination. There is a broad peak centered at about $16.5 \mathrm{eV}$, which is due to the $\mathrm{Cl} 3 \mathrm{~s}$. The intensity of $\mathrm{Cl} 3 s$ decreases upon the desorption of surface chlorides by thermal annealing. Fig. 7 shows that, in addition to the $\mathrm{PCl}$ formation, $\mathrm{PCl}_{2}$ and $\mathrm{PCl}_{3}$ are formed on the bombarded InP surface upon the adsorption of chlorine. The binding energies of $\mathrm{P} 2 p$ in $\mathrm{PCl}_{2}$ and $\mathrm{PCl}_{3}$ are higher than that in bulk InP by $3.9 \mathrm{eV}$ and $7.1 \mathrm{eV}$, respectively. It appears that the reactivity of the surface is promoted by ion bombardment to form higher chlorinated species. The saturation exposure of $\mathrm{Cl}_{2}$ on the bombarded surface is also higher than that on the annealed surface. Compared with the sputtered and annealed surface, more indium and phosphorus chlorides are formed on the bombarded InP surface at saturated chlorination. The increase in the reactivity of the bombarded surface is not due to ion implantation of argon. It is known that, after ion bombardment, argon is trapped in the InP substrate as an interstitial impurity with low equilibrium concentration [43]. The chemical affinity between argon and InP is so small that the increased reactivity of the bombarded surface should be mainly due to the surface inhomogeneity. $\mathrm{The} \mathrm{Ar}^{+}$-ion bombardment results in a roughened InP surface and generates inhomogeneity in the surface composition and structure. The damaged surface may consist of adatoms which exist in a configuration with dangling bonds or in a looser bonding structure. They are thus more reactive to chlorine and can be highly chlorinated.

Figs. 6 and 7 show that $\mathrm{InCl}_{3}, \mathrm{PCl}_{2}$ and $\mathrm{PCl}_{3}$ species desorb from the surface after heating the substrate to $250 \mathrm{~K}$. However, $\mathrm{InCl}_{2}, \mathrm{InCl}$ and $\mathrm{PCl}$ can still remain on the surface, as observed in the experiments performed on the sputtered and annealed surface. As described above, the ion bombardment can increase the surface reactivity with chlorine to form highly chlorinated indium and phosphorus species $\left(\mathrm{InCl}_{3}, \mathrm{PCl}_{2}\right.$ and $\left.\mathrm{PCl}_{3}\right)$. These chlorides are highly volatile and readily desorb from the surface at temperature below $250 \mathrm{~K}$. As a consequence, bombardment of the sample may enhance the etching rate of InP by chlorine to some degree. In this case, the etching rate may be more or less limited by the formation of the highly volatile products (i.e., $\mathrm{InCl}_{3}, \mathrm{PCl}_{2}$, and $\mathrm{PCl}_{3}$ ) at low temperatures.

\section{Conclusions}

The XPS study shows that the $\operatorname{InP}(100)-4 \times 2$ surface is an indium-rich surface with the presence of metallic indium atoms. These atoms may exist on the surface in the form of microdroplets and cover only a small fraction of the surface area. Chlorination of the $\operatorname{InP}(100)-4 \times 2$ surface causes changes in the surface composition and results in surface band bending. For chlorination to occur on the clean surface, $\mathrm{InCl}$ and $\mathrm{InCl}_{2}$ are the major indium chloride and $\mathrm{PCl}$ is the only phosphorous chloride upon the adsorption of chlorine. The clean InP surface can be regenerated by thermally annealing the chlorinated surface to $600 \mathrm{~K}$. $\mathrm{Ar}^{+}$-ion bombardment can create more reactive surface features that can be extensively chlorinated. The etching rate of the InP surface by chlorine may thus be enhanced at low temperature by irradiation of the sample with energetic ions.

\section{Acknowledgements}

This work was supported by SRRC and National Science Council under Grant No. NSC873-2613-M-213-016. We also express our appreciation to the beamline group at SRRC for their instrumental support.

\section{References}

[1] J.B. Malherbe, W.O. Barnard, Surf. Sci. 255 (1991) 309.

[2] T. Yoshikawa, S. Kohmoto, M. Anan, Y. Sugimoto, M. 
Sugomoto, K. Asakawa, Jpn J. Appl. Phys. Part 131 (1992) 4381.

[3] S.J. Pearton, Mater. Sci. Eng. B 10 (1991) 187.

[4] J. Massies, P. Devoldere, N.T. Linh, J. Vac. Sci. Technol. 15 (1978) 1353.

[5] M. Shimomura, N. Sanada, Y. Fukuda, P.J. Moller, Surf. Sci. 359 (1996) L451.

[6] M.M. Sung, C. Kim, H. Bu, D.S. Karpuzov, J.W. Rabalais, Surf. Sci. 322 (1995) 116.

[7] J. Massies, F. Lemaire-Dezaly, J. Appl. Phys. 57 (1985) 237.

[8] P. Soukiassian, P.S. Mangat, Y. Huttel, Z. Hurych, B. Gruzza, A. Porte, J. Vac. Sci. Technol. B 11 (1993) 1603.

[9] F. Lodders, J. Westhof, J.A. Schaefer, H. Hopfinger, A. Goldmann, S. Witzel, Z. Phys. B 83 (1991) 263.

[10] X. Wang, Appl. Surf. Sci. 33/34 (1998) 88.

[11] X. Hou, G. Dong, X. Ding, X. Wang, J. Phys. C 20 (1987) L121.

[12] C.B. Duke, Appl. Surf. Sci. 65 (1993) 543.

[13] M.M. Sung, J.W. Rabalais, Surf. Sci. 342 (1996) L1137.

[14] J. Woll, T. Allinger, V. Polyakov, J.A. Schaefer, A. Goldmann, W. Erfurth, Surf. Sci. 315 (1994) 293.

[15] V. Montgomery, R.H. Williams, R.R. Varma, J. Phys. C: Solid State Phys. 11 (1978) 1989.

[16] D.G. Lishan, E.L. Hu, J. Vac. Sci. Technol. B 8 (1990) 1951.

[17] S.C. McNevin, J. Vac. Sci. Technol. B 4 (1986) 1203.

[18] A.J. Murrell, R.J. Price, R.B. Jackman, J.S. Foord, Surf. Sci. 227 (1990) 197.

[19] A.T. Demos, H.S. Fogler, H. Etemad-Moghadam, M.E. Elta, J. Electrochem. Soc. 138 (1991) 1143.

[20] R. Behrisch (Ed.), Sputtering by Particles Bombardment II, Springer, Berlin, 1983.

[21] H.C. Duran, R. Cheung, W. Patrick, W. Bachtold, I. Pfund, G. Hahner, Microelectronic Eng. 35 (1997) 67.

[22] G.F. Doughty, S. Thoms, V. Law, C.D.W. Wilkinson, Vacuum 36 (1986) 803.

[23] M.C. Shih, M.B. Freiler, R. Scarmozzino, R.M. Osgood Jr., J. Vac. Sci. Technol. B 13 (1995) 43.
[24] W.C. Simpson, D.K. Shuh, J.A. Yarmoff, J. Vac. Sci. Technol. B 14 (1996) 2909.

[25] X. Jin, M. Yu, X. Wang, Chin. Phys. Lett. 2 (1985) 345.

[26] W.M. Lau, R.N.S. Sodhi, B.J. Flinn, K.H. Tan, G.M. Bancroft, Appl. Phys. Lett. 51 (1987) 177.

[27] C. Jardin, D. Robert, B. Achard, B. Gruzza, C. Pariset, Surf. Interface Anal. 10 (1987) 301.

[28] X. Jin, M. Yu, X. Wang, Chin. Phys. Lett. 7 (1987) 854.

[29] S. Abdellaoui, B. Gruzza, C. Pariset, M. Bouslama, C. Jardin, D. Robert, Surf. Sci. 208 (1989) L21.

[30] O. M'Hamedi, F. Proix, J.P. Lacharme, C.A. Sebenne, Surf. Sci. 199 (1988) 121.

[31] J.M. Moison, M. Bensoussan, J. Vac. Sci. Technol. 21 (1982) 315.

[32] W. Weiss, R. Hornstein, D. Schmeisser, W. Gopel, J. Vac. Sci. Technol. B 8 (1990) 715.

[33] K. Jacobi, W. Ranke, Prog. Surf. Sci. 10 (1981) 1.

[34] P. Drahten, W. Ranke, K. Jacobi, Surf. Sci. 77 (1978) L162.

[35] G.A. Somorjai, Chemistry in Two Dimensions Surface, Cornell University Press, Ithaca, NY, 1981.

[36] F.J. Himpsel, B.S. Meyerson, F.R. McFeely, J.F. Morar, A. Taleb-Ibrahima, J.A. Yarmorff, in: M. Campagna, R. Rosei (Eds.), Photoemission and Absorption Spectroscopy of Solids and Interfaces with Synchrotron Radiation, North-Holland, Amsterdam, 1990.

[37] P.R. Varekamp, W.C. Simpson, D.K. Durbin, V. Chakarian, J.A. Yarmoff, Phys. Rev. B 50 (1995) 14267.

[38] W.H. Hung, S.L. Wu, C.C. Chang, J. Phys. Chem. 102 (1998) 1141.

[39] J.A. Schaefer, F. Stietz, J. Woll, J. Vac. Sci. Technol. 11 (1993) 1497.

[40] F. Stietz, V. Persch, T. Allinger, J.A. Schaefer, G.J. Lapeyre, J. Electron Spectrosc. Relat. Phenom. 64/65 (1993) 413.

[41] F. Stietz, T. Allinger, V. Polyakov, J. Woll, A. Goldmann, W. Erfurth, G.J. Lapeyre, J.A. Schaefer, Appl. Surf. Sci. 104/105 (1996) 169.

[42] D.R. Lide (Ed.), CRC Handbook of Chemistry and Physics, CRC Press, Boca Raton, FL, 1994.

[43] J.S. Pan, A.T.S. Wee, C.H. Huan, H.S. Tan, K.L. Tan, J. Appl. Phys. 80 (1996) 6655. 